\title{
ATTITUDES OF LATVIAN CONSUMERS TO TRADITIONAL AND ECO-FRIENDLY FOOD PACKAGING MATERIALS: COMPARISON OF 2007 AND 2017
}

\author{
Sandra Muizniece-Brasava, Asnate Kirse \\ Latvia University of Life Sciences and Technologies, Latvia \\ sandra.muizniece@1lu.lv, asnate.kirse@1lu.lv
}

\begin{abstract}
Food packaging has an essential role in ensuring safe delivery of food products from 'farm to fork'. However, food packaging accounts for almost two-thirds of total packaging waste by volume and approximately $50 \%$ by weight of total packaging sales. Therefore, consumer attitudes of food packaging have the potential to contribute to and also counteract environmentally sustainable development.In order to assess consumer awareness and attitudes to traditional and biodegradable polymer food packaging materials in the market of Latvia, a 19-question survey was polled in 2007 and 2017. The survey was completed by 1000 respondents (50\% men, $50 \%$ women) from all regions of Latvia (Kurzeme, Zemgale, Vidzeme, Latgale and Riga) each year. The questions were related to consumer knowledge of traditional and eco-friendly packaging, their willingness to pay more for eco-friendly food packaging, as well the difference of packaging and recycling symbols.Compared to 2007, consumers would like to participate in the reduction of environmental pollution more frequently, however, they were not willing to pay more than $5 \%$ for eco-friendly food packaging in 2017.
\end{abstract}

Keywords: food packaging, consumers, attitudes, packaging waste, environmental pollution.

\section{Introduction}

Food packaging has an essential role in ensuring safe delivery of food products from "farm to fork". Food packaging is used to protect food from the influence of external factors, which can deteriorate the product and reduce its shelf life, to contain food, to provide a convenient use of the product and to inform the consumer [1]. More often than before packaging is becoming the main factor affecting consumer purchase choice, perception and food acceptance [2], therefore, packaging innovations aid in selling products in this competitive environment. Consequently, identifying consumer expectations of food packaging design and concept is important in order to avoid negative attitudes and lower sales [2].

Each year the quantity of packaging materials raises, accordingly the waste and the need for recycling of the used materials increases. Food packaging accounts for almost two-thirds of total packaging waste by volume and approximately $50 \%$ by weight of total packaging sales. Today, only $14 \%$ of the global plastic packaging materials are recycled ( $>60 \%$ in the EU) and based on the composition of materials it is expected that around $30 \%$ of plastic packaging materials may fail to be recycled or reused [3].

According to the Eurostat data from 2015 on packaging waste, number one packaging waste material within the last 10 years in the EU was paper and cardboard (34.7 million tonnes), followed by plastic packaging (15.8 million tonnes), glass (15.8 million tonnes), wood packaging (13.3 million tonnes) and metal packaging (4.6 million tonnes) [4].

Paper and cardboard are fairly easily recyclable materials; however, plastic packaging materials quite often consist of a different plastic type combination - multi-layer materials or blended plastics which can be too costly to separate and recycle [3]. Therefore, multi-layer biodegradable food packaging with high-barrier properties has gained recognition from a waste management point of view, as it could substitute non-recyclable and non-degradable multi-layer packaging materials currently used [5].

Nowadays, it is especially important to educate consumers on the advantages of environmentally friendly (bio-based, biodegradable, recyclable) packaging, based on the current issues on marine plastic pollution. Up to 13 million tonnes of plastic is dumped in oceans every year, leading to the engenderment of a large number of marine animals [6].

The potential to contribute to or counteract environmentally sustainable development is in the hands of consumers; therefore, consumer surveys are an important tool to understand the situation in the society. This study deals with the assessment of consumer awareness and attitudes to traditional and biodegradable polymer food packaging materials in the market of Latvia and analyses the differences of the results of consumer surveys conducted in 2007 and 2017. 


\section{Materials and methods}

In order to assess consumer awareness and attitudes to traditional and biodegradable polymer food packaging materials in the market of Latvia, twopaper-based multiple-choice question surveyswere developed: a 10-question survey in 2007 and a 19-question survey in 2017. They contained 10 identical questions and 9 additional questions were developed for the survey in 2017, as 10 years ago the implementation of biodegradable food packaging materials in the Latvian market had just started.

The results of 1000 respondents (50\% men, $50 \%$ women) were polled on each yearfrom all regions of Latvia (Kurzeme, Zemgale, Vidzeme, Latgale and Riga). The data are presented per regions and as a total average response of Latvian consumers. The mean distribution of respondents by age adolescents (younger than 20 years), 20-45 years old and older than 45 years - was $20.4 \%, 55.2 \%$ and $24.4 \%$ in 2007 and $25.5 \%, 44.2 \%$ and $30.3 \%$ in 2017, respectively.The mean distribution of respondents by education - basic, secondary, vocational and higher - was $18.2 \%, 25.7 \%, 19.3 \%$ and $36.8 \%$ in 2007 and $17.3 \%, 28.4 \%, 20.2 \%$ and $34.1 \%$ in 2017, respectively.

The questions were related to consumer knowledge of traditional and eco-friendly packaging, their awareness of packaging volume and waste, and adherence to waste sorting, the willingness to pay more for eco-friendly food packaging, as well the difference of packaging and recycling symbols. Consumers were also asked to rank packaging materials based on their eco-friendly features.

Statistical analysis of the data obtained was conducted with statistical software SPSS v20.0; significant differences $(p<0.05)$ were established by one-way analysis of variance (ANOVA).

\section{Results and discussion}

In recent years, the issue on the amount of packaging waste that is closely related to consumer products is becoming more urgent; therefore, it is very important to ascertain consumer opinion on the amount of packaging. As presented in Fig. 1, the situation in Latvia (shown in the first two columns), and across the regions has changed positively comparing the data from 2007 and 2017.In general,the respondents presume that the amount of packaging we use has decreased within the last 10 years(reduction of $15 \%$ on average), except the for Kurzeme region $(\mathrm{p}<0.05)$. Also, a positive trend can be observed - the number of respondents, who believe that there is not that much packaging used for food products, is gradually increasing (from 5 to $12 \%$ ), which could indicate that companies have started to utilize the available packaging solutions more rationally.

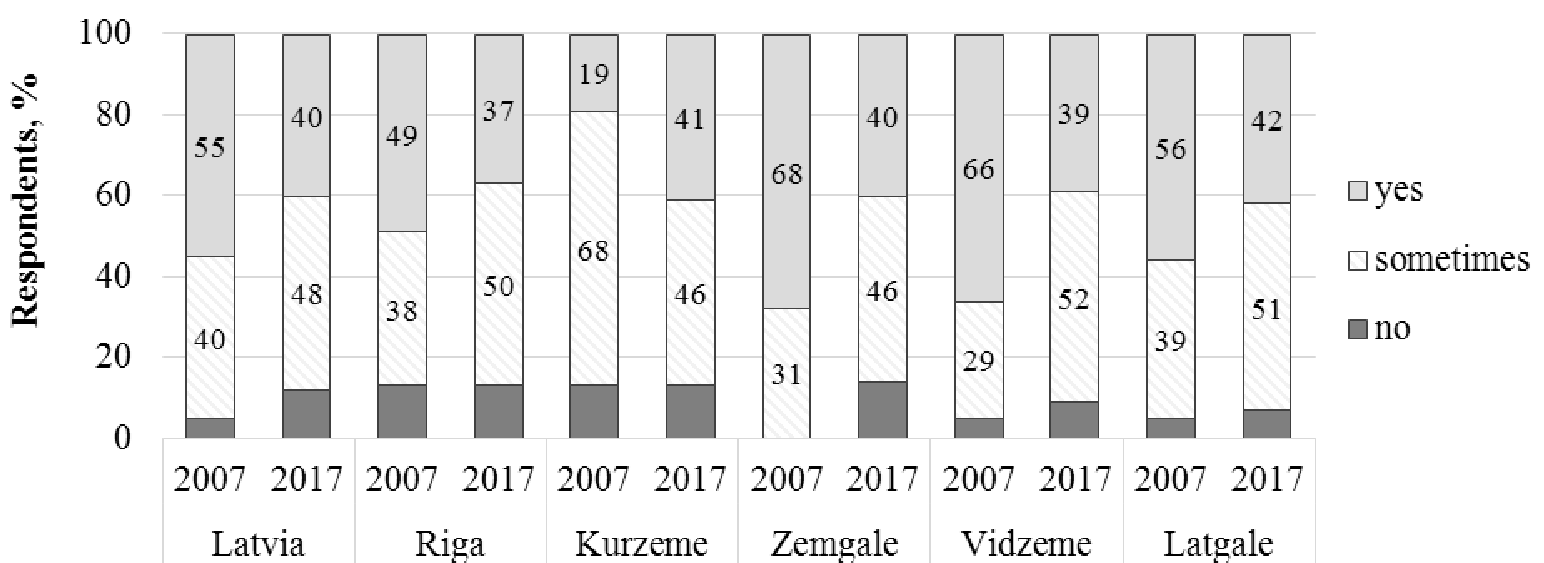

Fig. 1. Consumer opinion on whether too much packaging is used for food products

Most of the consumers pay attention to environmental issues (Fig. 2), however, the number ofrespondents, who are concerned or concernedsometimes about this issue, hasdropped from $96 \%$ to $87 \%$ over the past ten years in Latvia $(p>0.05)$.

More than $70 \%$ of Latvian consumers acknowledge that packaging materials have a different effect on environmental pollution both in 2007 and 2017 ( $p>0.05)$. A consumer survey of 2016 by researchers from the Lund University in Sweden showed that Swedes believe packaging material to have the main impact on sustainability [7], whereas a recent packaging research showed that the 
protective function of packaging contributes the most to sustainable development within environmental context [8].

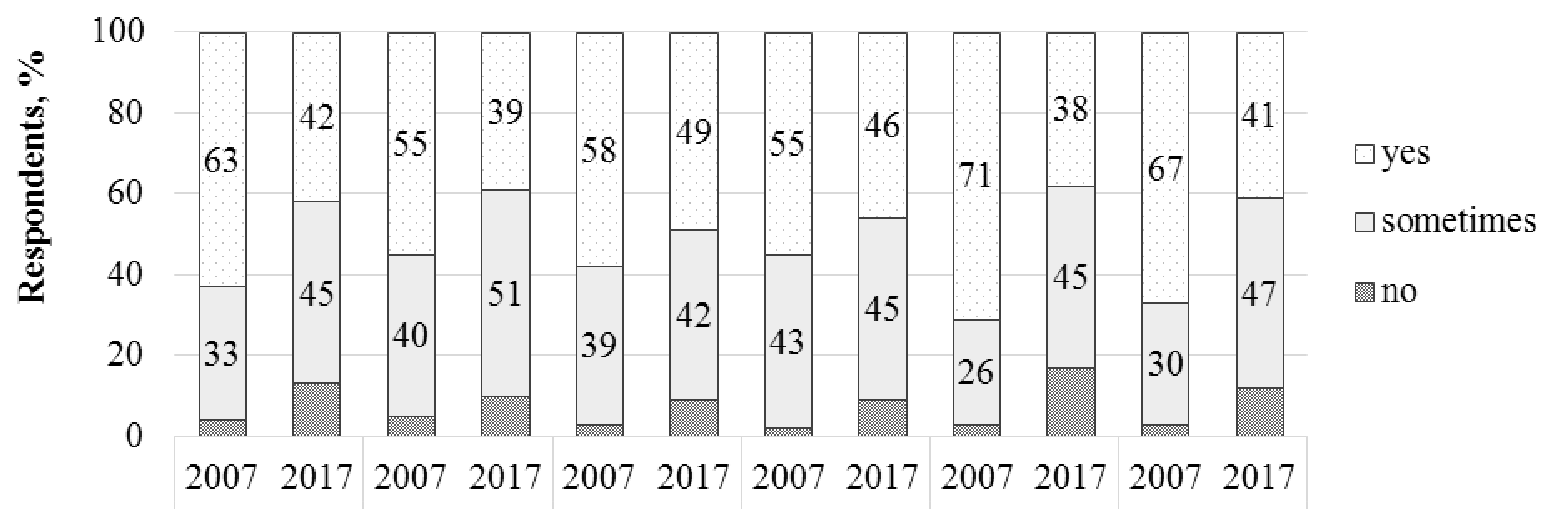

\begin{tabular}{l|l|l|l|l|l} 
Latvia & Riga & Kurzeme & Zemgale & Vidzeme & Latgale
\end{tabular}

Fig. 2.Viewpoint on whether consumers are concerned about environmental contamination with used packaging waste

With regards to consumer awareness level on eco-friendly / biodegradable packaging, a relatively large proportion of consumers in 2007 and 2017wasnearly informed or not informed at all about the availabilityof such packaging, a total of $90 \%$ and $78 \%$, respectively (Fig. 3). Although there is a tendency to awareness increase in the population, the rise is still very slow.Compared to Latvia on average and other regions, the most rapid increase occurred in Zemgale region, which could be related to the activities implemented by the university in Zemgale region - the Latvia University of Life Sciences and Technologies, thereby informing more inhabitants.

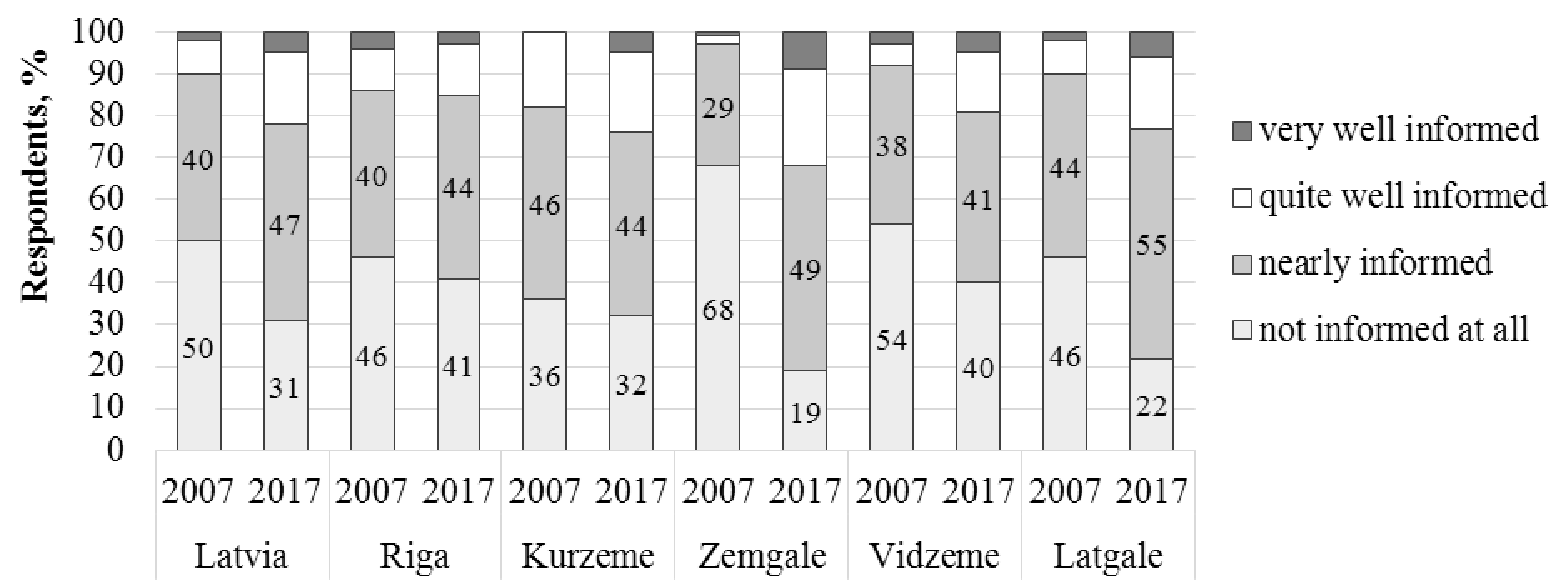

Fig. 3. Consumer awareness level on eco-friendly / biodegradable packaging

Based on the fact that food packaging is not just increasing in volume, but also in the diversity of materials, it is important to discover consumer knowlegde on environmental friendliness of packaging materials. Consumers ranked degradable polymers $(\mathrm{G})$, recyclable glass $(\mathrm{F})$ and paper and cardboard (E) as the top three groups ofeco-friendly packaging materials (Fig. 4), which totaled around $85 \%$ in 2007, and decreased by $25 \%$ in $2017(p<0.05)$. This could indicate that consumers pay more attention, e.g., to the fact that traditional polymer materials are different, and some of them can be processed quite successfully; as compared to 2007, the number of respondents(up to $8 \%$ more), who believe that traditional polymers (A) can be environmentally friendly, has increased in 2017.Unfortunately, over the past 10 years, the number of respondents ranking laminated carboard packages $(\mathrm{C})$ as quite eco-friendly has increased (up to $12 \%$ more in some regions).Similarly, Swedish consumers noted that paper-based packaging can be considered more environmentally friendly compared to plastic and metal in 2016 [7]. 


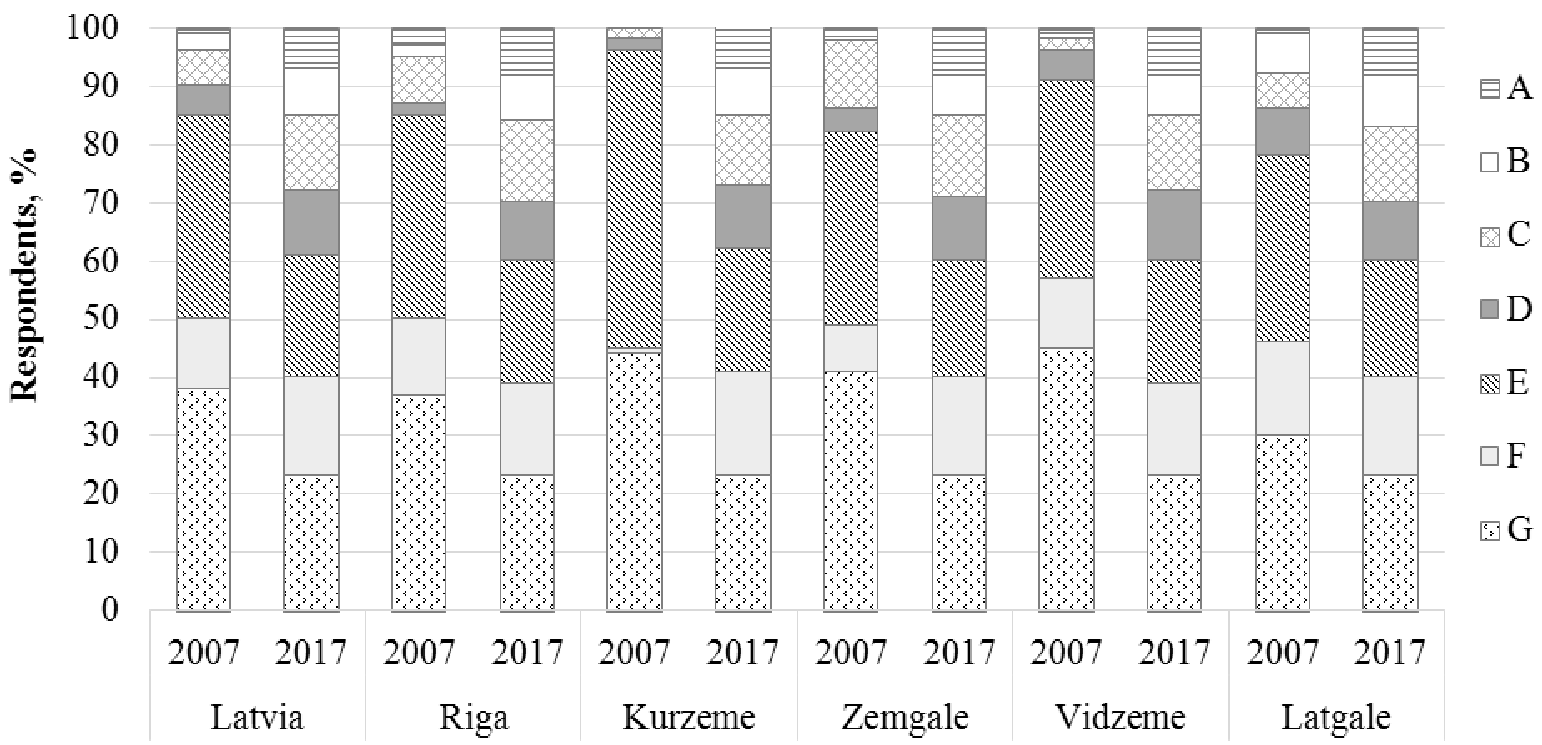

Fig. 4. Consumer opinion on most environmentally friendly food packaging:

A - conventional polymers, $\mathbf{B}$ - metal cans, foil, $\mathbf{C}$ - laminated cardboard packages, D - disposable glass, $\mathrm{E}$ - paper, cardboard, F - recyclable glass, $\mathbf{G}$ - degradable polymers

The comparison of the tax rate for packaging and disposable tableware and accessories over the last 10 years shows the rise in the tax rates by differentiating packaging materials according to their environmental friendliness (Table 1). In 2009, oxidegradable plastic source materialswereseperated in a new packaging material group and given a lower tax rate compared to conventional materials.Starting 2014, an additional group of polymers - polystyrene source materials - was created and taxed a higher rate compared to other materials, because at the moment it is considered one of the least environmentally friendly packaging materials [9].

Table 1

Tax rates for packaging of goods and products and for disposable tableware and accessories in Latvia [10]

\begin{tabular}{|c|c|c|c|c|c|c|}
\hline \multirow{2}{*}{$\begin{array}{c}\text { Type of material of packaging of goods and } \\
\text { products and disposable tableware and } \\
\text { accessories }\end{array}$} & \multicolumn{7}{|c|}{ Tax rateper kg, EUR } \\
\cline { 2 - 8 } & $\mathbf{2 0 0 6}$ & $\mathbf{2 0 0 7}$ & $\mathbf{2 0 0 8}$ & $\begin{array}{c}\mathbf{2 0 0 9}- \\
\mathbf{2 0 1 3}\end{array}$ & $\begin{array}{c}\mathbf{2 0 1 4} \\
\mathbf{2 0 1 6}\end{array}$ & $\mathbf{2 0 1 7}$ \\
\hline Of glass source materials & 0.06 & 0.23 & 0.28 & 0.36 & 0.44 & 0.44 \\
\hline $\begin{array}{c}\text { Of plastic (polymer) source materials, except } \\
\text { bioplastic or oxy-degradable plastic (after } \\
\text { 2009) and polystyrene source materials (after } \\
\text { 2014) }\end{array}$ & 0.14 & 0.57 & 0.85 & 0.92 & 1.22 & 1.22 \\
\hline Of metal source materials & 0.09 & 0.34 & 0.64 & 1.00 & 1.10 & 1.10 \\
\hline $\begin{array}{c}\text { Of wood, paper and cardboard or other natural } \\
\text { fibre and bioplastic source materials }\end{array}$ & 0.02 & 0.07 & 0.21 & 0.21 & 0.24 & 0.24 \\
\hline Of oxy-degradable plastic source materials & - & - & - & 0.64 & 0.70 & 0.70 \\
\hline Of polystyrene source materials & - & - & - & - & 1.56 & 2.20 \\
\hline
\end{tabular}

Another inportant issue on eco-friendly packaging materials is their higher cost compared to conventional materials. Survey data from 2007 showed that $17 \%$ of respondents would certainly be willing to pay more for eco-friendly packaging materials, and $35 \%$ of respondents would possibly do so, while only $13 \%$ of respondents would certainly pay more and $40 \%$ would probably pay more in 2017; this concludes that more than a half of Latvian population would be willing to pay morefor ecofriendly packaging materials, without significant differences between years 2007 and $2017(p>0.05)$. With regards to numbers, $39 \%$ of respondents would be willing pay up to $5 \%$ more for eco-friendly 
packaging (Fig. 5); in contrast, the second largest group (29\%) was composed of respondents who would not pay more to protect the environment.

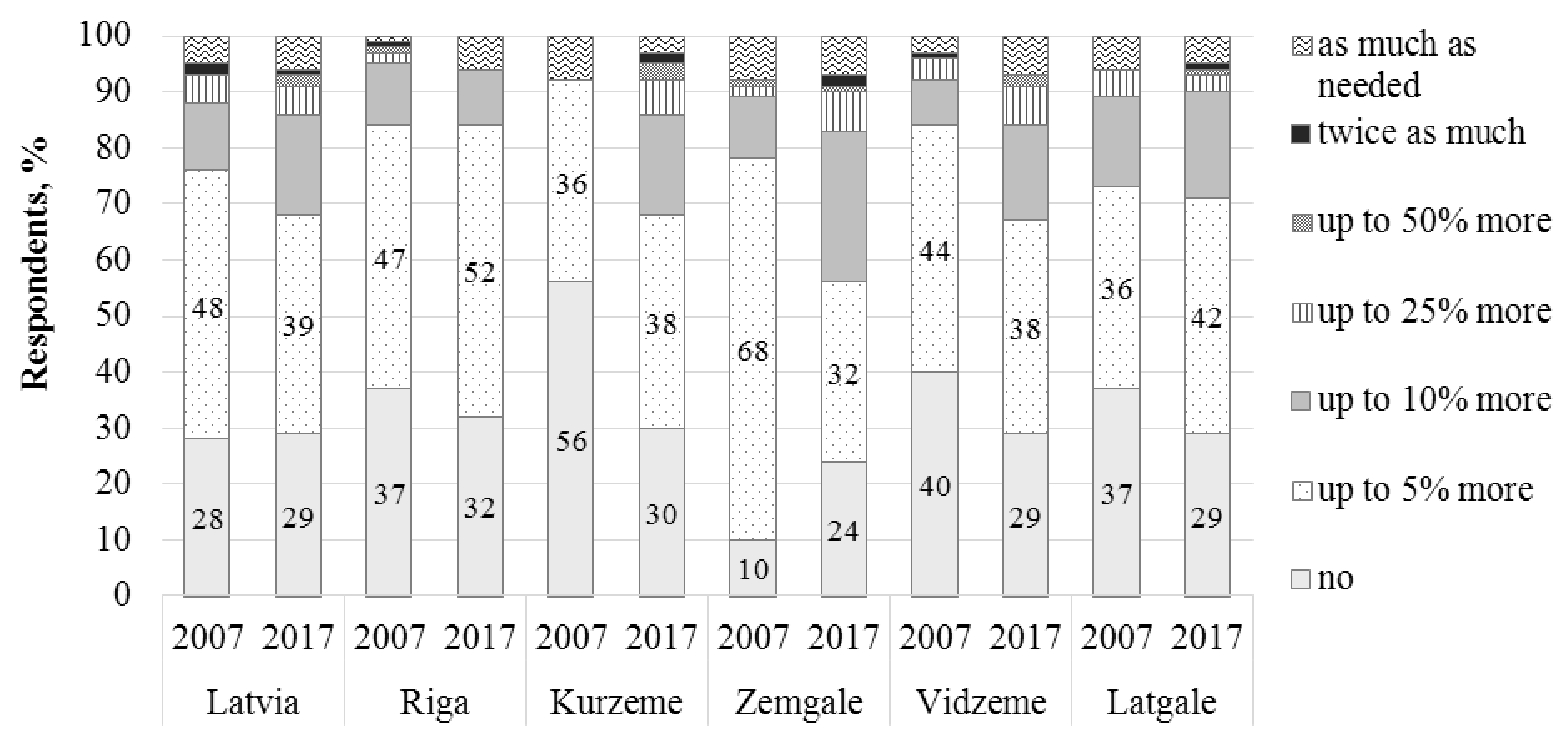

Fig. 5. Consumer willingness to pay more for eco-friendly (biodegradable) food packaging materials compared to conventional materials

Consumer attitude towards the introduction of new biodegradable materials for food packaging on a scale from 1 (very good) to 6 (rejecting) is variable (Fig. 6). Most of the respondents (70\%) evaluated such initiative with points from 1 to 3 in 2017, yet in 2007 there were $13 \%$ more of the positive answers. This could be explained by the decrease in the intensity of the first information wave, as responsible institutions in Latvia started to spread the information on environmentally friendly packaging, which had a similar appearance to traditional polymer packaging, in 2007.

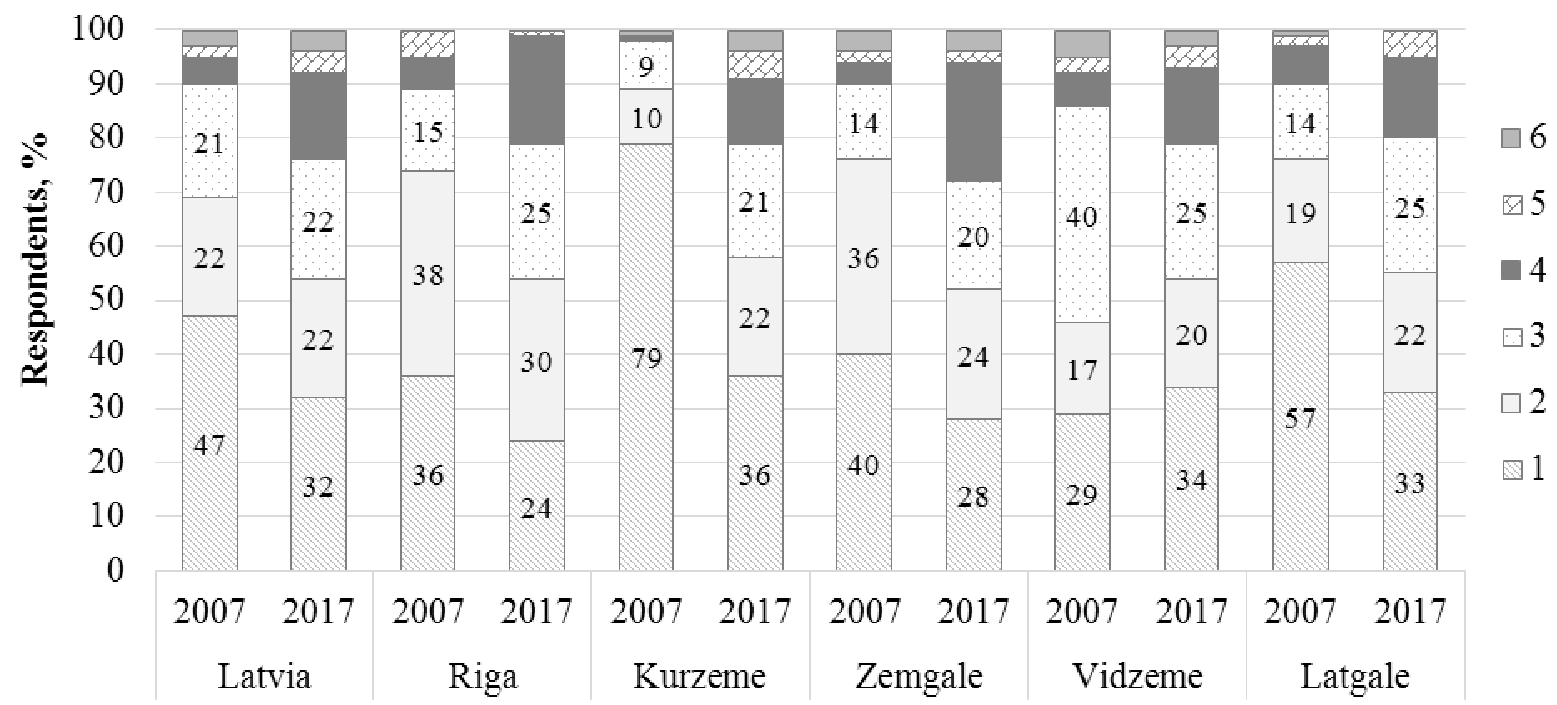

Fig. 6. Consumer attitude towards introduction of new biodegradable materials for food packaging (scale 1- very good to 6- rejecting)

Based on the diversity of food products in grocery stores, an increase in different types of shopping bags can be observed. As consumers buy food daily, the issue of chosing the optimal shopping bag is topical. Consumers tend to use shopping bags made from eco-friendly materials more than before. If in 2007 shopping bags made from traditional polymers we used by $20 \%$ of respondents, but $18 \%$ prefered textile materials and $35 \%$ - paper bags, then in 2017 only $16 \%$ use shopping bags made from traditional polymers and $32 \%$ of respondents (increase of $14 \%$ ) prefer to use bags made from textile materials. Today, it has also become a trend to follow zero waste 
movement and recent technologies offer personalised approach to customised textile shopping bags, which promotes better visibility for enterprises.

The question of packaging and waste sorting by consumerswas brought up for the first time at a national level more than 10 years ago, when within theNational Waste Management Plan for 20062012 authorities intended to establish 10 waste management areas in Latvia [11].Packaging material and recycling symbols also became topical only after 2006, as before there was no need for the majority of consumers to get acquainted with these issues. Therefore, questions on the recognition of such symbols (Fig. 7) and waste sorting and recycling awareness were not included in the survey of 2007.

a)

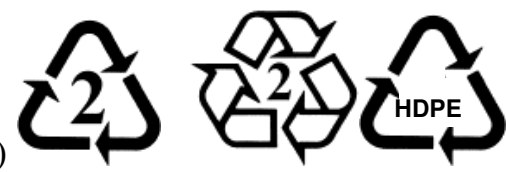

b)

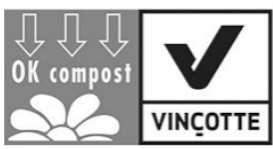

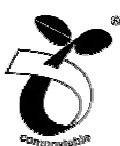

c)

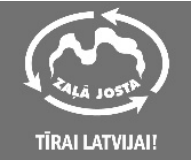

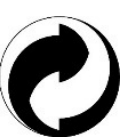

Fig. 7. Packaging material and recycling symbols to be recognised by consumers: a - high-density polyethylene [12]; b - OK compost labels[13]; c - "Zạ̧ājosta" Ltd. logo [14] and Green Dot trademark [15]

Even though the information on recycling and packaging material symbols (also known as resin identification codes) has been accesible in the media, less than $15 \%$ of respondents in 2017 (except for Zemgale $-22 \%$ ) believe that they are able to identify packaging material labels. When asked to look at several labeling type,s less than $19 \%$ of respondents were able to recognize packaging material labels (Fig. 7a), more than $60 \%$ of respondents did not recognize packaging material recycling/compost labels (Fig. 7b), however, at least $57 \%$ of Latvian respondents had seen and could identify the logo of "Zạ̧ā josta" Ltd. and Green Dot trademark (Fig. 7c).

As presented in Fig. 8, approx. one fifth of Latvianpopulation adheres to waste sorting(not significant differences among regions, $\mathrm{p}>0.05$ ), while $40 \%$ of the respondents do it sometimes, hence, this is the proportion of the population open to change as long as they have a greater incentive to do so. On the other hand, as much as $20 \%$ of respondents do not sort waste and another comparatively large group of respondents would like to adhere to waste sorting, but do not have the opportunity. Therefore, this is an issue that needs to be addressed on the national level.

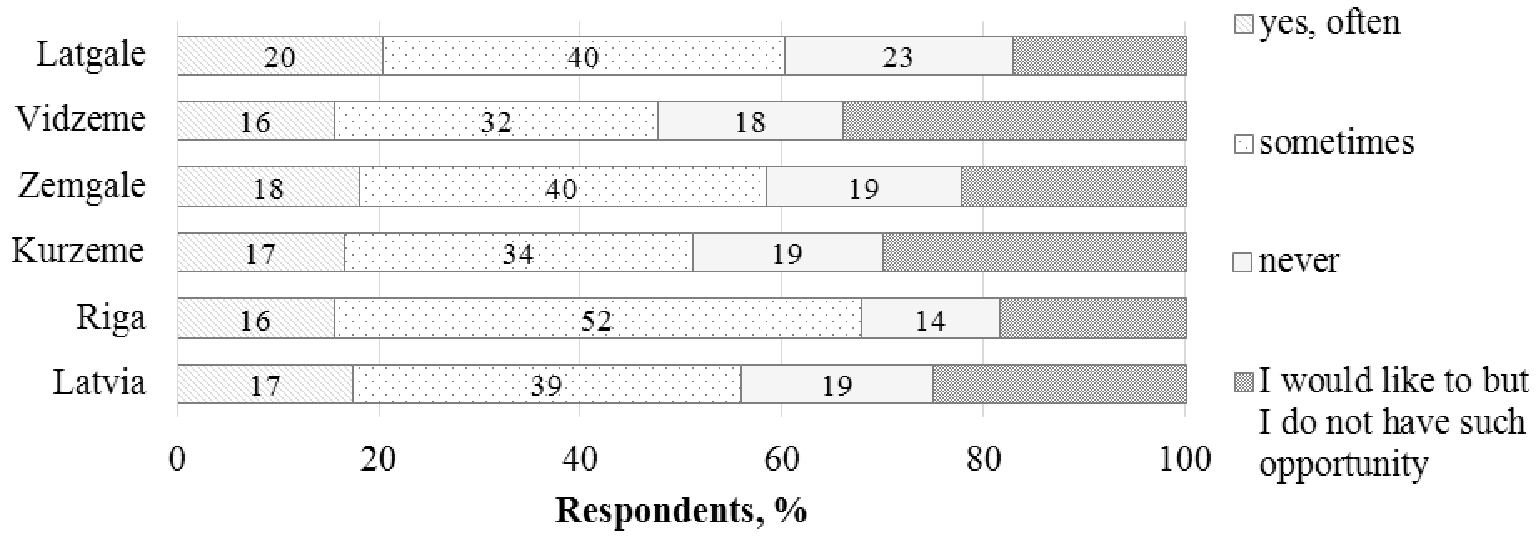

Fig. 8. Consumer adherence to waste sorting in household or waste recycling bins

In addition, as shown by the research of Lindh et al. (2016), food waste in the EU draws up to $20 \%$ and about $20-25 \%$ of food waste in households is related to packaging [7]. Thus, it is also possible to influence more the numbers of the wasted food, if the changes in current packaging materials are considered.

\section{Conclusions}

Nowadays, more than ever environmental pollution with discarded packaging materials is a pressing issue and most of the consumers $(87 \%)$ pay attention to environmental issues, yet, the average Latvian consumer believes that within the last 10 years the amount of packaging we use has 
decreased by $7 \%$. A large segment of consumers (78\%) does not feel adequately informed on ecofriendly/biodegradable packaging; however, compared to 2007, the number of informed consumers has increased by $12 \%$. A positive trend on the national level is the tax differentiation on packaging materials based on their effect on environment. Zero waste movement is slowly gaining recognition in Latvia and consumers are gradually moving towards the use of shoppings bags from textile materials (increase of $14 \%$ ). Latvian consumers were poorly educated on packaging and recycling symbols in 2017. Compared to 2007, consumers would like to participate in the reduction of environmental pollution more frequently, however, they were not willing to pay more than $5 \%$ for eco-friendly food packaging in 2017.

\section{References}

[1] Marsh K., BugusuB. Food Packaging - Roles, Materials, and Environmental Issues. Journal of Food Science, vol. 72, no. 3, 2007, pp. 39-55.

[2] Gelici-Zeko M., Lutters D., ten Klooster R., Weijzen P.L.G. Studying the Influence of Packaging Design on Consumer Perceptions (of Dairy Products) Using Categorizing and Perceptual Mapping.Packaging Technology and Science, vol. 26, no. 4, 2013, pp. 215-228.

[3] Ellen MacArthur Foundation. The New Plastics Economy - Catalysing Action (2017) [online] [07.05.2018]. Available at: https://www.ellenmacarthurfoundation.org/assets/downloads/NewPlastics-Economy_Catalysing-Action_13-1-17.pdf

[4] Eurostat. Packaging waste statistics. [online] [07.05.2018]. Available at: http://ec.europa.eu/eurostat/statistics-explained/index.php/Packaging_waste_statistics

[5] Dilkes-Hoffman L.S., Lane J.L., Grant T. etc. Environmental impact of biodegradable food packaging when considering food waste. Journal of Cleaner Production, vol. 180, 2018, pp. 325-334.

[6] Haward M. Plastic pollution of the world's seas and oceans as a contemporary challenge in ocean governance. Nature Communications, vol. 9, no. 667, 2018, pp. 1-3.

[7] Lindh H., Olsson A., Williams H. Consumer Perceptions of Food Packaging: Contributing to or Counteracting Environmentally Sustainable Development? Packaging Technology and Science, vol. 29, no. 1, pp 3-23.

[8] Fernqvist F., Olsson A., Spendrup D. What's in it for me? Food packaging and consumer responses, a focus group study. British Food Journal, vol. 117, no. 3, pp. 1122-1135.

[9] Jin Y., Xia J., Pan Z. etc. Polystyrene microplastics induce microbiota dysbiosis and inflammation in the gut of adult zebrafish. Environmental Pollution, vol. 235, 2018, pp. 322-329.

[10] Tax Rates for the Packaging of Goods and Products and for Disposable Tableware and Accessories. Natural Resources Tax Law, Annex 7. [online] [07.05.2018]. Available at: https://likumi.lv/ta/id/124707-dabas-resursu-nodokla-likums\#piel7\&pd = 1

[11] National Waste Management Plan for 2013-2020 by Ministry of Environmental Protection and Regional Development of the Republic of Latvia. [online] [07.05.2018]. Available at: http://www.varam.gov.lv/in_site/tools/download.php?file = files/text/Likumd/_projekti/VIDE/atkr it_plans/VARAMPl_120213_atkritumi.doc

[12] Republic of Latvia Cabinet Regulation No 140 (adopted 2 April 2002) Packaging Classification and Marking Regulations. [online] [07.05.2018]. Available at: https://likumi.lv/doc.php?id = 60915

[13] OK compost \& OK compost HOME. [online] [07.05.2018]. Available at: http://www.okcompost.be/en/recognising-ok-environment-logos/ok-compost-amp-ok-composthome/

[14] "Zaḷājosta" Ltd. logo. [online] [07.05.2018]. Available at: http://www.zalajosta.lv/en/download$\log 0$

[15] LatvijasZaļaispunkts trademark. [online] [07.05.2018]. Available at: http://www.zalais.lv/en/about-us/logo/ 